\title{
Spontaneous Alternating Copolymerization of 1-Silyloxy-1,3-dienes and Unsaturated Cyclic Anhydrides
}

\author{
Akinori TAKASU, Shin-Ichiro INOUE, Yoshihito INAI, and Tadamichi HiRABAYASHI ${ }^{\dagger}$ \\ Department of Environmental Technology and Urban Planning, \\ Graduate School of Engineering, Nagoya Institute of Technology, \\ Gokiso-cho, Showa-ku, Nagoya 466-8555, Japan
}

(Received December 25, 2000; Accepted January 29, 2001)

\begin{abstract}
Silyloxy-1,3-dienes, i.e., 1-butadienyloxytrimethylsilane (BdTMS) or 1-butadienyloxytertbutyldimethylsilane (BdTBDMS) and unsaturated cyclic anhydrides, containing maleic anhydride (MAn), citraconic anhydride (CAn), and itaconic anhydride (IAn) were found to form charge transfer complexes (CTC) in benzene. Equilibrium constants, $K$, of the complexes were calculated by the Benesi-Hildebrand equation using UV spectroscopy to be 0.4 -1.0. Spontaneous copolymerizations of silyloxydienes with unsaturated cyclic anhydrides were established from 25 to $75 \mathrm{~mol} \%$ of BdTMS in the feed. All polymers obtained had molar composition of 50/50 irrespective of feed molar ratios. Interestingly, molar ratio of 1,4- and 3,4-addtion structure seems to be influenced by $K$ of CTC. Desilylation and successive lactonization of poly(BdTMS-alt-MAn) were conducted. Conversions of lactonization were beyond Flory's limit $(86.5 \%)$ being nearly $100 \%$ due to intramolecular reactions of neighboring hydroxyl groups and cyclic anhydride in alternating copolymers.

KEY WORDS Spontaneous Copolymerization / Charge Transfer Complex (CTC) / Alternating Copolymer / Silyloxydiene / Unsaturated Cyclic Anhydride / Desilylation / Lactonization /
\end{abstract}

Most polymerization reactions require an initiator, catalyst, or high energy radiation, but there have often been reports on copolymerizations in the absence of added initiator. ${ }^{1}$ Copolymerization of this type is based on a specific combination of one monomer with nucleophilic reactivity and another with high electrophilicity. $^{2}$ In some systems, copolymerization proceeds via radical mechanism, whereas in others a zwitterion is involved. Copolymerizations have been extensively researched by Saegusa ${ }^{3}$ and Hall. ${ }^{4}$ Ziwitteric character is favored by donors, such as alkoxy and dialkylamino groups, at the carbenium center and strong acceptors, such as two cyano groups, at the carbanion center. Diradical character is favored by acceptor groups, such as diesters and cyano-esters, at the acceptor end, and aryl and vinyl groups as donors. Zwitterionic tetramethylenes initiate ionic homopolymerization, while diradical tetramethylenes initiate alternating copolymerization. ${ }^{4}$ Homopolymerization of maleic anhydride (MAn) is difficult but there is a vast survey about its copolymers in the literature. Most studies report the formation of alternating copolymers via a charge transfer complex (CTC) of the electron deficient MAn and electron rich comonomer. ${ }^{4-7}$

Spontaneous copolymerizations of $E$-1-butadienyloxytrimethylsilane (BdTMS) or $E$-1-butadienyloxytertbutyldimethylsilane (BdTBDMS) with MAn, citraconic anhydride (CAn), and itaconic anhydride (IAn) were carried out. BdTMS and BdTBDMS are 1,3-dienes with hydroxyl groups masked by silyl groups and strong electron donating monomers. There are few data concerning the polymerization of BdTMS, but many applications of silyloxydienes in organic synthesis ${ }^{8-14}$ including synthesis of natural products, for example, anasamycin antibiotic, awamycin, ${ }^{10}$ a derivative of an aphid pigment, qui-

${ }^{\dagger}$ To whom correspondence should be addressed. none $\mathrm{A},{ }^{11}$ and phosphatase inhibitor, dysidiole. ${ }^{13} \mathrm{Al}-$ though we succeeded in aldol-type group transfer polymerization of BdTMS ${ }^{15-18}$ and hydrogenation of the polymer leading to completely alternating copolymer of ethylene and vinyl alcohol, ${ }^{19}$ radical polymerization of BdTMS has not been reported except for our results on the copolymerization of BdTMS with styrene and methyl methacrylate (MMA) in the presence of radical initiator. ${ }^{20}$ In our preliminary experiments, homopolymerization of BdTMS did not occurr even in the presence of radical initiator. ${ }^{15}$ However spontaneous copolymerization of BdTMS with cyclic anhydrides is expected to proceed via spontaneous process and the higher alternating tendency of the copolymer should be obtained.

Itaconic acid is present in some fungi (Aspergillus terreus, $A$. itaconicus, etc.). Commercially, itaconic acid is produced by cultivation of Aspergillus terreus with molasses or glucose ${ }^{21}$ and citraconic acid is derived from itaconic acid. Effective utilization of these natural resources as precursors for the production of new polymeric materials is needed from the standpoint of environmental technology. ${ }^{22}$ Recently, we reported the synthesis of biodegradable polyesters by ring-opening copolymerization of IAn or CAn with 1,2-epoxybutane ${ }^{23}$ or polycondensation of CAn with ethylene glycol. ${ }^{24}$

Attention has been also directed to the permeation and active transport of particular ions through membranes of synthetic polymers containing lactone structures. ${ }^{25}$ Such polymers can be synthesized by polymerizing unsaturated lactone monomers or intramolecular reaction of two neighboring substituents on a copolymer chain so as to form ester bonds. However, unsaturated lactone monomers often show low polymerizabilities and substituents of simple copolymer are not always arranged to favor intramolecular lactonization. Hirooka et $a l$. reported the hydrolysis and lactonization of poly(butyl vinyl ether-alt-methyl methacrylate) copolymer. ${ }^{26}$ 
However, the degree of lactonization did not exceed Flory's limit $(86.5 \%)^{27}$ even in alternating copolymer. After desilylation, alternating copolymers obtained in this study always had one cyclic anhydride group and hydroxyl group per repeating unit, separated from those in the neighboring units by spacer containing rigid double bonds. More effective intramolecular lactonization was promised in the specially-designed alternating copolymers, in which a pair of neighboring units should be kept apart by the third unit free from the intramolecular reaction. $^{28}$

\section{EXPERIMENTAL}

\section{Materials}

Trimethylchlorosilane, MAn, CAn, and zinc chloride were purchased from Nacalai Tesque, Inc. (Kyoto, Japan). tert-Butyldimethylchlorosilane (Tokyo Kasei Kogyo Co., Ltd., Tokyo) and $n$-butyllithium ( $n$-BuLi) (Kanto Chemical Co., Inc, Tokyo) were obtained commercially. Itaconic anhydride (IAn) was kindly supplied by Iwata Chemical Co., Ltd. (Shizuoka, Japan). $N$ Phenylmaleimide (NPMI) was purchased from Wako Pure Chemicals (Osaka, Japan). HCl/1,4-dioxane (4 N) was obtained from Kokusan Chemical Works, Ltd. (Tokyo). CAn was purified by distillation under reduced pressure. MAn and IAn were purified by recrystallization from chloroform. Crotonaldehyde, trimethylchlorosilane, triethylamine, benzene, dimethyl sulfoxide (DMSO), $N, N$-dimethylformamide (DMF), chloroform $\left(\mathrm{CHCl}_{3}\right)$, methanol, $n$-hexane, and diethyl ether were conventionally purified by distillation.

\section{Measurement}

FT-IR spectra in $\mathrm{KBr}$ were recorded using a JASCO FT/IR-430 spectrometer and a $100 \% \mathrm{KBr}$ disk was used as a reference. ${ }^{1} \mathrm{H}$ and ${ }^{13} \mathrm{C}$ NMR spectra were taken on a JEOL JNM-GX $400\left(400 \mathrm{MHz}\right.$ for $\left.{ }^{1} \mathrm{H}\right)$ in $\mathrm{CDCl}_{3}$ at room temperature. All chemical shifts were expressed as $\delta$ from tetramethylsilane (TMS). UV absorptions were measured with a JASCO V-550 UV/vis spectrometer at $25^{\circ} \mathrm{C}$. Number average molecular weight $\left(M_{\mathrm{n}}\right)$ and polydispersity $\left(M_{\mathrm{w}} / M_{\mathrm{n}}\right)$ of the copolymers were determined by size-exclusion chromatography (SEC) calibrated with polystyrene standards using a system of Tosoh HLC 803 D with a Tosoh RI-8020 detector and Tosoh G 2000-, G 3000-, G 4000-, and G5000-HXL columns (eluent: tetrahydrofuran, temperature: $40^{\circ} \mathrm{C}$ ).

\section{Preparation of 1-Butadienyloxytrimethylsilane (BdTMS)}

BdTMS was prepared according to Danishefsky's procedure. $^{8,9}$ Crotonaldehyde $200 \mathrm{~mL}(2.41 \mathrm{~mol})$, triethylamine $400 \mathrm{~mL}(2.86 \mathrm{~mol})$, zinc chloride $6.85 \mathrm{~g}(0.05$ $\mathrm{mmol}$ ), and benzene $500 \mathrm{~mL}$ were added to a $2 \mathrm{~L}$ threenecked flask under nitrogen atmosphere. To the mixture, trimethylchlorosilane $360 \mathrm{~mL} \quad(2.83 \mathrm{~mol})$ was added, and then was refluxed at $60^{\circ} \mathrm{C}$ for $70 \mathrm{~h}$. After the reaction was complete, the reaction mixture was cooled to room temperature and filtered. The filtrate was distilled (bp $61^{\circ} \mathrm{C} / 65 \mathrm{mmHg}$ ) to give BdTMS, of which $E$ isomer $(99 \%)$ could be isolated ( $200.4 \mathrm{~g}$ in $59 \%$ yield).
Preparation of E-1-Butadienyloxytert-butyldimethylsilane (BdTBDMS)

BdTBDMS was prepared by exchange reaction of the silyl group from BdTMS. BdTMS $38.5 \mathrm{~mL}$ ( $0.17 \mathrm{~mol})$ was dissolved in $300 \mathrm{~mL}$ of $\mathrm{THF}$ in a $2 \mathrm{~L}$ three-necked flask under nitrogen atmosphere and put into dry ice/methanol bath at $-78^{\circ} \mathrm{C} . n-\mathrm{BuLi}$ hexane solution $(1.54 \mathrm{~mol}$ $\left.\mathrm{L}^{-1}\right) 160 \mathrm{~mL}(0.25 \mathrm{~mol})$ was dropped into the solution and stirred at $-78^{\circ} \mathrm{C}$ for $1 \mathrm{~h}$ and $27^{\circ} \mathrm{C}$ for $2 \mathrm{~h}$. $t$ Butyldimethylchlorosilane $32.2 \mathrm{~g}(0.21 \mathrm{~mol})$ in $100 \mathrm{~mL}$ THF solution was added to the mixture at $27^{\circ} \mathrm{C}$ and stirred for $2 \mathrm{~h}$. THF and $\mathrm{Me}_{3} \mathrm{SiBu}$ were removed by evaporation and the reaction mixture was distilled under reduced pressure to give BdTBDMS as a $E$-isomer $20.3 \mathrm{~g}$ in $65 \%$ yield (bp $57^{\circ} \mathrm{C} / 7 \mathrm{mmHg}$ ).

\section{Copolymerization of BdTMS with MAn}

A typical experimental procedure is as follows. In a dry glass tube, a mixture of $0.20 \mathrm{~g}(1.43 \mathrm{mmol})$ of BdTMS and $0.429 \mathrm{~g}(4.37 \mathrm{mmol})$ of MAn were dissolved in 4.8 $\mathrm{mL}$ benzene at room temperature under nitrogen atmosphere. The mixture were frozen and the tube was sealed under vacuum. Polymerization was carried out at $60^{\circ} \mathrm{C}$ for $8 \mathrm{~h}$. After the reaction, the mixture was poured into $n$-hexane, and the supernatant was removed by decantation. After reprecipitation from $\mathrm{CHCl}_{3}$ solution into $n$ hexane as a non-solvent, the polymeric material was collected and dried in vacuo to give $0.10 \mathrm{~g}$ (15.5\% yield, Run 1 in Table II).

IR (KBr disk) $2959\left(v_{\mathrm{C}-\mathrm{H}}\right), 1858,1781\left[v_{\mathrm{C}=\mathrm{O}}(\right.$ cyclic anhydride)], 1657 [ $v_{\mathrm{CH}=\mathrm{CH}}($ cis $\left.)\right], 1226\left(v_{\mathrm{C}-\mathrm{O}-\mathrm{C}}\right), 1080 \mathrm{~cm}^{-1}$ $\left(v_{\text {Si-O }}\right)$.

${ }^{1} \mathrm{H} \mathrm{NMR}\left(\mathrm{CDCl}_{3}, 1.0 \mathrm{wt} \%, 27^{\circ} \mathrm{C}, \mathrm{TMS}\right) \delta 6.64-6.26$ $\left[\mathrm{CH}=\mathrm{CHOSi}\left(\mathrm{CH}_{3}\right)_{3}\right], \quad 5.93-5.41 \quad[\mathrm{CH}=\mathrm{CHCHOSi}-$ $\left.\left(\mathrm{CH}_{3}\right)_{3}\right], 4.79\left[\mathrm{CH}=\mathrm{CHOSi}\left(\mathrm{CH}_{3}\right)_{3}\right], 4.69-4.48 \quad[\mathrm{CH}=$ $\left.\mathrm{CHCHOSi}\left(\mathrm{CH}_{3}\right)_{3}\right], \quad 3.26 \quad\left[\mathrm{CH}_{2} \mathrm{CHCH}=\mathrm{CHOSi}\left(\mathrm{CH}_{3}\right)_{3}\right]$, $2.97(\mathrm{CHC}=\mathrm{O}), 2.79-2.45\left[\mathrm{CH}_{2} \mathrm{CH}=\mathrm{CHCHOSi}\left(\mathrm{CH}_{3}\right)_{3}\right]$, 1.79-1.45 $\left[\mathrm{CH}_{2} \mathrm{CHCH}=\mathrm{CHOSi}\left(\mathrm{CH}_{3}\right)_{3}\right], \quad 0.19 \quad[\mathrm{CH}=$ $\mathrm{CHOSi}\left(\mathrm{CH}_{3}\right)_{3}$ ], $0.07 \mathrm{ppm}\left[\mathrm{CH}=\mathrm{CHCHOSi}\left(\mathrm{CH}_{3}\right)_{3}\right]$.

${ }^{13} \mathrm{C} \mathrm{NMR}\left(\mathrm{CDCl}_{3}, 5.0 \mathrm{wt} \%, 27^{\circ} \mathrm{C}, \mathrm{TMS}\right) \delta 173.4-170.2$ $(\mathrm{C}=\mathrm{O}), 146.4-143.6\left[\mathrm{CH}=\mathrm{CHOSi}\left(\mathrm{CH}_{3}\right)_{3}\right], 134.5[\mathrm{CH}=$ $\left.\mathrm{CHCHOSi}\left(\mathrm{CH}_{3}\right)_{3}\right], 126.8\left[\mathrm{CH}=\mathrm{CHCHOSi}\left(\mathrm{CH}_{3}\right)_{3}\right], 105.5$ $\left[\mathrm{CH}=\mathrm{CHOSi}\left(\mathrm{CH}_{3}\right)_{3}\right], 72.2,70.8\left[\mathrm{CH}=\mathrm{CHCHOSi}\left(\mathrm{CH}_{3}\right)_{3}\right]$, $52.3(C H C=\mathrm{O}), 44.5\left[\mathrm{CH}_{2} \mathrm{CH}=\mathrm{CHCHOSi}\left(\mathrm{CH}_{3}\right)_{3}\right], 40.2$ $(C \mathrm{HC}=\mathrm{O}), 36.9\left[\mathrm{CH}_{2} \mathrm{CHCH}=\mathrm{CHOSi}\left(\mathrm{CH}_{3}\right)_{3}\right], 33.3\left[\mathrm{CH}_{2^{-}}\right.$ $\left.\mathrm{CHCH}=\mathrm{CHOSi}\left(\mathrm{CH}_{3}\right)_{3}\right], \quad 1.9, \quad 1.3 \quad\left[\mathrm{CH}=\operatorname{CHOSi}\left(\mathrm{CH}_{3}\right)_{3}\right]$, $0.8,-0.6 \mathrm{ppm}\left[\mathrm{CH}=\mathrm{CHCHOSi}\left(\mathrm{CH}_{3}\right)_{3}\right]$.

\section{Copolymerization of BdTMS with CAn}

The method of preparation was similar to that for the copolymerization of BdTMS and MAn. Yield, 25.9\% (Run 3 in Table III).

IR $(\mathrm{KBr}$ disk $) 2958\left(v_{\mathrm{C}-\mathrm{H}}\right), 1851,1783$ [ $\left(v_{\mathrm{C}=\mathrm{O}}\right.$ (cyclic anhydride)], 1659 [ $v_{\mathrm{CH}=\mathrm{CH}}($ cis $\left.)\right], 1218\left(v_{\mathrm{C}-\mathrm{O}-\mathrm{C}}\right), 1087 \mathrm{~cm}^{-1}$ $\left(v_{\mathrm{Si}-\mathrm{O}}\right)$.

${ }^{1} \mathrm{H}$ NMR $\left(\mathrm{CDCl}_{3}, 1.0 \mathrm{wt} \%, 27^{\circ} \mathrm{C}, \mathrm{TMS}\right) \delta 6.26[\mathrm{CH}=$ $\left.\mathrm{CHOSi}\left(\mathrm{CH}_{3}\right)_{3}\right], 6.00-5.40\left[\mathrm{CH}=\mathrm{CHCHOSi}\left(\mathrm{CH}_{3}\right)_{3}\right], 4.67$ $\left[\mathrm{CH}=\mathrm{CHOSi}\left(\mathrm{CH}_{3}\right)_{3}\right], 4.37\left[\mathrm{CH}=\mathrm{CHCHOSi}\left(\mathrm{CH}_{3}\right)_{3}\right], 2.92$ $\left[\mathrm{CH}_{2} \mathrm{CHCH}=\mathrm{CHOSi}\left(\mathrm{CH}_{3}\right)_{3}\right], 2.62(\mathrm{CHC}=\mathrm{O}), 2.38\left[\mathrm{CH}_{2^{-}}\right.$ $\left.\mathrm{CH}=\mathrm{CHCHOSi}\left(\mathrm{CH}_{3}\right)_{3}\right], \quad 1.48 \quad\left[\mathrm{CH}_{2} \mathrm{CHCH}=\mathrm{CHOSi}-\right.$ $\left.\left(\mathrm{CH}_{3}\right)_{3}\right], 1.39\left(\mathrm{CH}_{3} \mathrm{C}\right), 0.17 \quad\left[\mathrm{CH}=\mathrm{CHOSi}\left(\mathrm{CH}_{3}\right)_{3}\right], 0.07$ ppm $\left[\mathrm{CH}=\mathrm{CHCHOSi}\left(\mathrm{CH}_{3}\right)_{3}\right]$.

${ }^{13} \mathrm{C} \mathrm{NMR}\left(\mathrm{CDCl}_{3}, 5.0 \mathrm{wt} \%, 27^{\circ} \mathrm{C}\right.$, TMS $) \delta 175.4(\mathrm{CHC}$ 
$=\mathrm{O}), 170.3(\mathrm{CC}=\mathrm{O}), 145.3\left[\mathrm{CH}=\mathrm{CHOSi}\left(\mathrm{CH}_{3}\right)_{3}\right], 137.7$ $\left[\mathrm{CH}=\mathrm{CHCHOSi}\left(\mathrm{CH}_{3}\right)_{3}\right], 125.4\left[\mathrm{CH}=\mathrm{CHCHOSi}\left(\mathrm{CH}_{3}\right)_{3}\right]$, $107.5\left[\mathrm{CH}=\mathrm{CHOSi}\left(\mathrm{CH}_{3}\right)_{3}\right], \quad 71.5 \quad[\mathrm{CH}=\mathrm{CHCHOSi}-$ $\left.\left(\mathrm{CH}_{3}\right)_{3}\right], 57.3,55.1(\mathrm{CHC}=\mathrm{O}), 48.1(\mathrm{CC}=\mathrm{O}), 42.7\left[\mathrm{CH}_{2^{-}}\right.$ $\left.\mathrm{CH}=\mathrm{CHCHOSi}\left(\mathrm{CH}_{3}\right)_{3}\right], \quad 33.5 \quad\left[\mathrm{CH}_{2} \mathrm{CHCH}=\mathrm{CHOSi}-\right.$ $\left.\left(\mathrm{CH}_{3}\right)_{3}\right], 29.1\left[\mathrm{CH}_{2} \mathrm{CHCH}=\mathrm{CHOSi}\left(\mathrm{CH}_{3}\right)_{3}\right], 19.4, \quad 15.5$ $\left(\mathrm{CCH}_{3}\right), 0.4,0,-0.6 \mathrm{ppm}\left[\mathrm{OSi}\left(\mathrm{CH}_{3}\right)_{3}\right]$.

\section{Copolymerization of BdTMS with IAn}

The method of preparation was similar to that for the copolymerization. Yield, $13.6 \%$ (Run 1 in Table IV).

IR (KBr disk) $2957\left(v_{\mathrm{C}-\mathrm{H}}\right), 1854,1779\left[v_{\mathrm{C}=\mathrm{O}}\right.$ (cyclic anhydride $)], \quad 1660 \quad\left(v_{\mathrm{CH}=\mathrm{CH}}\right), 1227 \quad\left(v_{\mathrm{C}-\mathrm{O}-\mathrm{C}}\right) 1096 \mathrm{~cm}^{-1}$ $\left(v_{\text {Si-O }}\right)$.

${ }^{1} \mathrm{H}$ NMR $\left(\mathrm{CDCl}_{3}, 1.0 \mathrm{wt} \%, 27^{\circ} \mathrm{C}\right.$, TMS $\delta 6.33-5.96$ $\left[\mathrm{CH}=\mathrm{CHOSi}\left(\mathrm{CH}_{3}\right)_{3}\right], \quad 5.57-5.26 \quad[\mathrm{CH}=\mathrm{CHCHOSi}-$ $\left.\left(\mathrm{CH}_{3}\right)_{3}\right], 4.38\left[\mathrm{CH}=\mathrm{CHOSi}\left(\mathrm{CH}_{3}\right)_{3}\right], 4.23[\mathrm{CH}=\mathrm{CHCHOSi}-$ $\left.\left(\mathrm{CH}_{3}\right)_{3}\right], 3.25 \quad\left[\mathrm{CH}_{2} \mathrm{CHCH}=\mathrm{CHOSi}\left(\mathrm{CH}_{3}\right)_{3}\right], 3.23-2.69$ $\left(\mathrm{CH}_{2} \mathrm{C}=\mathrm{O}\right), \quad 2.69-2.12 \quad\left[\mathrm{CH}_{2} \mathrm{CH}=\mathrm{CHCHOSi}\left(\mathrm{CH}_{3}\right)_{3}\right]$, $2.03-1.43\left[\mathrm{CH}_{2} \mathrm{CHCH}=\mathrm{CHOSi}\left(\mathrm{CH}_{3}\right)_{3}, \quad \mathrm{CH}_{2} \mathrm{C}\right], \quad 0.18$ $\left[\mathrm{CH}_{2} \mathrm{CHCH}=\mathrm{CHOSi}\left(\mathrm{CH}_{3}\right)_{3}\right], 0.03$ ppm $[\mathrm{CH}=\mathrm{CHCHOSi}-$ $\left(\mathrm{CH}_{3}\right)_{3}$ ].

\section{Desilylation and Lactonization of Poly(BdTMS-alt-MAn) (1a)}

Poly(BdTMS-alt-MAn) (1a) $200 \mathrm{mg}(0.83 \mathrm{mmol})$ was dissolved in $30 \mathrm{~mL} \mathrm{1,4-dioxane.} \mathrm{To} \mathrm{the} \mathrm{solution,} 0.3 \mathrm{~mL}$ (1.2 mmol) of $4 \mathrm{~N} \mathrm{HCl} / 1$,4-dioxane was added and stirred for $3 \mathrm{~h}$ at room temperature. As the reaction proceeded, a white precipitate was observed. The precipitate was collected and purified by reprecipitation from DMSO to chloroform three times to give polymeric materials $97 \mathrm{mg}(70 \%)$.

IR (KBr disk) $3432\left(v_{\mathrm{O}-\mathrm{H}}\right), 2928\left(v_{\mathrm{C}-\mathrm{H}}\right), 1860\left[v_{\mathrm{C}=\mathrm{O}}(\mathrm{cy}-\right.$ clic anhydride $)], 1779\left[v_{\mathrm{C}=\mathrm{O}}(\gamma\right.$-lactone and cyclic anhydride) $], 1723,1636 \quad\left[v_{\mathrm{C}=\mathrm{O}}\right.$ (carboxylic acid) $], 1218$ $\left(v_{\mathrm{C}-\mathrm{O}-\mathrm{C}}\right), 978\left[\delta_{\mathrm{H}-\mathrm{C}=\mathrm{C}-\mathrm{H}}(\operatorname{trans})\right], 754 \mathrm{~cm}^{-1}\left[\delta_{\mathrm{H}-\mathrm{C}=\mathrm{C}-\mathrm{H}}\right.$ (cis)].

${ }^{1} \mathrm{H}$ NMR (DMSO- $d_{6}, 1.0 \mathrm{wt} \%, 27^{\circ} \mathrm{C}$, TMS) $\delta 9.73-9.50$ $\left(\mathrm{CH}_{2} \mathrm{CH}=\mathrm{O}\right), 6.00-5.73\left(\mathrm{CH}_{2} \mathrm{CH}=\mathrm{CHCH}\right), 5.73-5.40$ $\left(\mathrm{CH}_{2} \mathrm{CH}=\mathrm{CHCH}\right), \quad 5.26 \quad(\mathrm{COOH}), \quad 5.03 \quad\left(\mathrm{CH}_{2} \mathrm{CH}=\right.$ $\mathrm{CHCH}), 3.26(\mathrm{CHCOOH}), 3.11\left[\mathrm{CH}_{2} \mathrm{CH}=\mathrm{O}, \mathrm{CHCO}(\mathrm{cy}-\right.$ clic anhydride)], 2.26-1.40 ppm $\left(\mathrm{CH}_{2} \mathrm{CH}=\mathrm{CHCH}, \mathrm{CH}_{2}\right.$ $\mathrm{CHCH}_{2}, \mathrm{CH}_{2} \mathrm{CHCH}_{2}$ ).

\section{RESULTS AND DISCUSSION}

\section{Charge Transfer Complex (CTC) Formation}

Mixing of BdTMS and acceptor monomer including MAn, CAn, IAn, and NPMI in benzene led to an immediate yellow color development, considered due to formation of a charge transfer complex (CTC). The probable equilibrium between the two monomers and CTC would be

$$
\mathrm{BdTMS}+\mathrm{A} \stackrel{K}{\rightleftharpoons} \mathrm{CTC}
$$

(A: unsaturated cyclic anhydride)

At $[\mathrm{BdTMS}]_{0} \gg[\mathrm{A}]_{0}$, the classical Benesi-Hildebrand method $^{29}$ is useful to determine the equilibrium constant $(K)$. Observed absorbance at a given wavelength $(\mathrm{d})$ is thus related to $K$ by eq 2 .
Table I. Formation of the charge transfer complex (CTC) of 1butadienyloxytrimethylsilane (BdTMS) with acceptor monomers ${ }^{\mathrm{a}}$

\begin{tabular}{ccccc}
\hline Acceptor monomer & $Q^{\mathrm{b}}$ & $e^{\mathrm{b}}$ & $k^{\mathrm{c}}$ & $\varepsilon^{\mathrm{c}}$ \\
\hline MAn & 0.23 & 2.25 & 0.44 & 172.5 \\
CAn & 0.87 & 1.75 & 0.96 & 107.4 \\
IAn & 2.50 & 0.88 & 0.59 & 58.1 \\
NPMI & 1.26 & 1.69 & $<0.01$ & - \\
\hline
\end{tabular}

${ }^{\mathrm{a}}$ Solv., benzene; temp., $25^{\circ} \mathrm{C} .{ }^{\mathrm{b}}$ Data from ref $30 .{ }^{\mathrm{c}}$ Binding constant and extinction coefficient of the CTC, determined by UV measurement using Benesi-Hidebrand relationship.

$$
[\mathrm{A}]_{0} \times L / d=[\mathrm{BdTMS}]_{0}^{-1} \times K^{-1} \times \varepsilon^{-1}+\varepsilon^{-1}
$$

Where $[\mathrm{BdTMS}]_{0}$ and $[\mathrm{A}]_{0}$ are initial concentrations of BdTMS and acceptor monomer, respectively. $L$ is the optical path length and $\varepsilon$ is extinction coefficient of CTC at a given wavelength. Since the charge transfer band of the complex appears in the same region where both monomers themselves are absorbed, it is difficult to use the peak maximum of CTC to determine $K$ of the CTC. Therefore, measurements were carried out at $340 \mathrm{~nm}$ for MAn-BdTMS, $375 \mathrm{~nm}$ for CAn-BdTMS, and $309 \mathrm{~nm}$ for IAn-BdTMS, respectively, though monomers showed weak absorptions in this range. Plots of $[\mathrm{A}]_{0} / d$ vs. $1 /$ $[\mathrm{BdTMS}]_{0}$ yielded a straight line except for NPMI, from which it may be deduced that BdTMS and cyclic anhydrides form $1: 1$ complexes. $K$ obtained from the plots are listed with $Q$ and $e^{30}$ of the acceptor monomers in Table I. $K$ and $\varepsilon$ were 0.44 and 172.5 for MAn, 0.96 and 107.4 for CAn, and 0.59 and 58.1 for IAn, respectively. Equilibrium constants for these pairs were from $0.1-$ 1.0, which were classified to groups of spontaneous alternating copolymerization near/at room temperature reported by Yamashita et al. ${ }^{31}$

\section{Copolymerization of BdTMS or BdTBDMS with MAn}

Copolymerization of BdTMS and MAn was carried out at $60^{\circ} \mathrm{C}$ for $8 \mathrm{~h}$. The copolymerization proceeded homogeneously in all cases (Table II). Polymer yields were 2.9 $22.9 \%$. Polymer was analyzed by ${ }^{1} \mathrm{H},{ }^{13} \mathrm{C}$ NMR and IR spectra. In every case, compositions of BdTMS and MAn units in poly(BdTMS-alt-MAn) (1a) were 50/50, determined by ${ }^{1} \mathrm{H}$ NMR intensity of the peak at 0.19 and 0.07 ppm $\left[-\mathrm{OSi}\left(\mathrm{CH}_{3}\right)_{3}\right]$ and peak at $2.97 \mathrm{ppm}(\mathrm{CHCH}=\mathrm{O})$. Analysis of ${ }^{1} \mathrm{H}$ and ${ }^{13} \mathrm{C}$ NMR spectra revealed that not only 1,4- but also 3,4- addition of BdTMS occur in the course of copolymerization. The peaks at $6.64-6.26$ and $4.79 \mathrm{ppm}$ in the ${ }^{1} \mathrm{H}$ NMR spectrum and $146.4-143.6$ and $105.5 \mathrm{ppm}$ in ${ }^{13} \mathrm{C}$ NMR spectrum (Figure 1) should be ascribed to the 3,4-addition structure. ${ }^{1} \mathrm{H}$ NMR spectra distinguished the methyl protons ascribed to silyl group in 3,4-addition structure from those in the 1,4addition structure, which appeared at $0.19 \mathrm{ppm}$ and 0.07 ppm, respectively. The peaks were used to estimate 1,4and 3,4-addition structures. If interaction between the monomers causes the alternating copolymerization, the microstructure of the BdTMS unit in this copolymer must be rich in cis 1,4-addition structure, because the charge-transfer type of interaction is the strongest in the case of cis overlapping through the transition state, similar to that in the Diels-Alder reaction of butadiene. ${ }^{32}$ In the copolymerization of butadiene and MAn re- 
$\mathrm{CH}_{2}=\mathrm{CH}-\mathrm{CH}=\left.\right|_{\mathrm{OR}} ^{\mathrm{CH}}++\left.\left.\right|_{\mathrm{C}} ^{\mathrm{CH}=}\right|_{\mathrm{O}} ^{\mathrm{CH}}$

BdTMS, $\mathrm{R}=\mathrm{Si}\left(\mathrm{CH}_{3}\right)_{3}$

BdTBDMS, $\mathrm{R}=\mathrm{Si}(t-\mathrm{Bu})\left(\mathrm{CH}_{3}\right)_{2}$

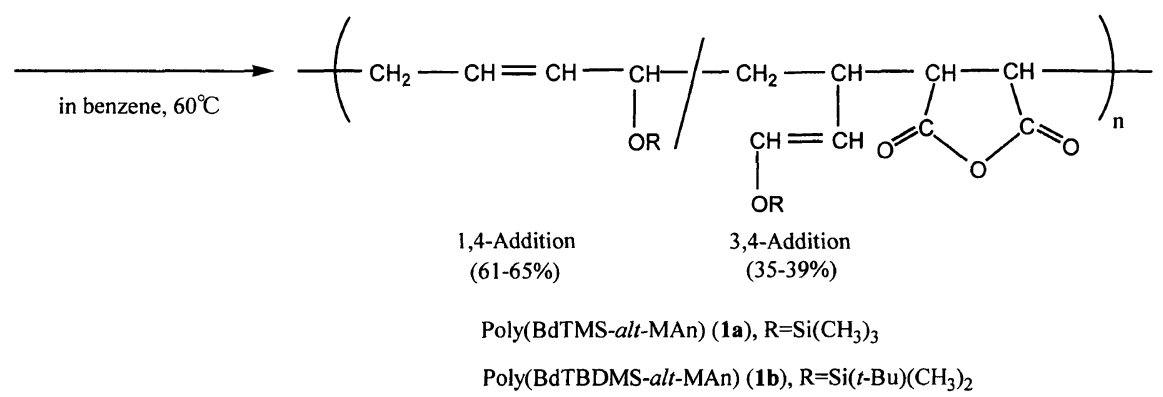

Scheme 1. Spontaneous copolymerization of BdTMS or BdTBDMS with MAn.

Table II. Copolymerizations of silyloxydienes with maleic anhydride (MAn) ${ }^{\mathrm{a}}$

\begin{tabular}{|c|c|c|c|c|c|c|c|}
\hline \multirow{2}{*}{ Run } & \multirow{2}{*}{ Monomer } & \multirow{2}{*}[\text{diene}]{$_{0} /[\mathrm{MAn}]_{0}^{\mathrm{b}}$} & Yield & \multirow{2}{*}{$M_{\mathrm{n}}^{\mathrm{c}} \times 10^{-4}$} & \multirow{2}{*}{$M_{\mathrm{w}} / M_{\mathrm{n}}^{\mathrm{c}}$} & \multirow{2}{*}{$\frac{{\text { [diene }] /[\mathrm{MAn}]^{\mathrm{d}}}_{\mathrm{mol} \%}}{\mathrm{~m}}$} & \multirow{2}{*}{ 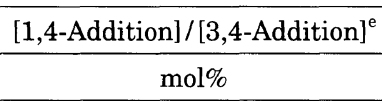 } \\
\hline & & & $\mathrm{mol} \%$ & & & & \\
\hline 1 & BdTMS & $25 / 75$ & 15.5 & 3.29 & 2.6 & $50 / 50$ & $64 / 36$ \\
\hline 2 & BdTMS & $37 / 63$ & 21.8 & 4.13 & 2.6 & $51 / 49$ & $61 / 39$ \\
\hline 3 & BdTMS & $50 / 50$ & 22.9 & 9.64 & 2.2 & $50 / 50$ & $63 / 37$ \\
\hline 4 & BdTMS & $62 / 38$ & 4.8 & 4.70 & 2.5 & $52 / 48$ & $65 / 35$ \\
\hline 5 & BdTMS & $75 / 25$ & 2.9 & $-^{f}$ & $-^{f}$ & $52 / 48$ & $61 / 39$ \\
\hline 6 & BdTBDMS & $25 / 75$ & 5.2 & 18.8 & 1.7 & $50 / 50$ & $64 / 36$ \\
\hline 7 & BdTBDMS & $37 / 63$ & 8.0 & 28.4 & 1.7 & $51 / 49$ & $64 / 36$ \\
\hline 8 & BdTBDMS & $50 / 50$ & 12.0 & 52.1 & 1.7 & $51 / 49$ & $63 / 37$ \\
\hline 9 & BdTBDMS & $62 / 38$ & 6.1 & 43.3 & 2.1 & $52 / 48$ & $63 / 37$ \\
\hline 10 & BdTBDMS & $75 / 25$ & 3.2 & 34.7 & 2.0 & $52 / 48$ & $65 / 35$ \\
\hline
\end{tabular}

${ }^{\mathrm{a}}{\text { [diene }]_{0}+[\mathrm{MAn}]_{0}=1.2 \mathrm{~mol} \mathrm{~L}}^{-1}$; solv., benzene; temp., $60^{\circ} \mathrm{C}$; time, $8 \mathrm{~h} .{ }^{\mathrm{b}}$ Feed molar ratio of silyoxydiene to MAn. ${ }^{\mathrm{c}}$ Determined by SEC in THF (polystyrene standards). ${ }^{\mathrm{d}}$ Molar ratio of silyoxydiente and MAn unit in polymer, determined by ${ }^{1} \mathrm{H} \mathrm{NMR}$ in $\mathrm{CDCl}_{3} .{ }^{\mathrm{e}} \mathrm{Molar}$ ratio of 1,4-addition unit to 3,4-addition unit in the polymer, determined by ${ }^{1} \mathrm{H}$ NMR in $\mathrm{CDCl}_{3} .{ }^{\mathrm{f}}$ Insoluble in THF.

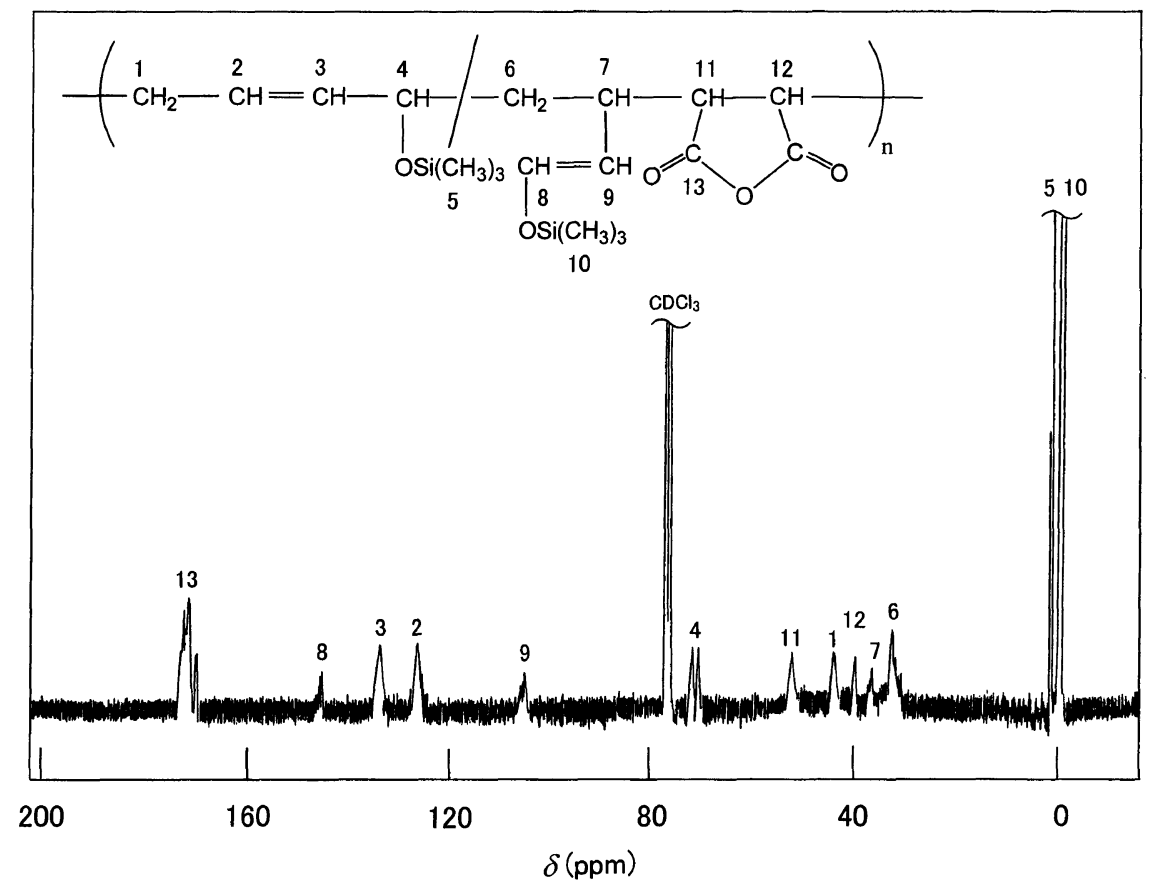

Figure 1. ${ }^{13} \mathrm{C}$ NMR spectrum of poly(BdTMS-alt-MAn) (1a) in $\mathrm{CDCl}_{3}\left(27^{\circ} \mathrm{C}, 100 \mathrm{MHz}\right)$. 
ported by Yamashita et al., cis 1,4-addition structure was predominant (ca. 90\%) relative to trans 1,4structure. ${ }^{31}$ In the IR spectra of copolymer 1a, only a strong peak at $1657\left(v_{\mathrm{H}-\mathrm{C}=\mathrm{C}-\mathrm{H}}\right)$ was observed, indicating that the polymers mostly consist of cis 1,4-structure because the peak of trans 1,4-structure may appear at 1675. These results strongly suggested that alternating copolymerization of BdTMS and MAn took place via the CTC complex.

Spontaneous copolymerization of BdTBDMS with MAn was also carried out under the same experimental conditions to investigate the effect of the silyl group (Run 6-10 in Table II). The yields of $\mathbf{1 b}$ were $5.2-$ $12.0 \%$, indicating a maximun yield at the feed molar ratio of 50/50. The molar ratios of BdTBDMS and MAn units in the copolymer were always 50/50 irrespective of feed molar ratios. $M_{\mathrm{n}} \mathrm{s}$ were more than 5 times as those of the corresponding alternating copolymer $1 \mathrm{a}$ unexpectedly. The tert-butyldimethylsilyl group influenced the solubility of the copolymer as well as polymerizability. While alternating copolymer $1 \mathrm{a}$ with more than $1.0 \times 10^{5}$ of $M_{\mathrm{n}}$ was insoluble in THF and diethyl ether, alternating copolymers $1 \mathrm{~b}$ with $2.0 \times 10^{5}-5.0 \times 10^{5}$ of $M_{\mathrm{n}}$ were soluble in both solvents. The higher $M_{\mathrm{n}}$ of poly (BdTBDMS-alt-MAn) (1b) may be due to the higher flexibility of main chain in organic solvents.

\section{Copolymerization of BdTMS with CAn}

Copolymerization of BdTMS and CAn occurred spontaneously and gave the poly(BdTMS-alt-CAn) (2) under the same conditions as for the copolymerization of BdTMS with MAn. The results are summarized in Table
III. The compositions of BdTMS and CAn in copolymer 2 ([BdTMS]/[CAn]) determined from ${ }^{1} \mathrm{H}$ NMR intensity ratio of peak at $0.17,0.07 \mathrm{ppm}\left[\mathrm{OSi}\left(\mathrm{CH}_{3}\right)_{3}\right]$ and peak at $1.39 \mathrm{ppm}\left(\mathrm{CH}_{3} \mathrm{C}\right)$ were almost 50/50 regardless of monomer feed ratio. Examination of ${ }^{1} \mathrm{H}$ and ${ }^{13} \mathrm{C}$ NMR spectra revealed the 3,4-addition as well as 1,4-addition. The 1,4-addition structure determined by ${ }^{1} \mathrm{H}$ NMR intensity ratio of peak at $0.17 \mathrm{ppm}\left[\mathrm{CH}=\mathrm{CHOSi}\left(\mathrm{CH}_{3}\right)_{3}\right]$ and 0.07 ppm $\left[\mathrm{CH}=\mathrm{CHCHOSi}\left(\mathrm{CH}_{3}\right)_{3}\right]$ was $74-78 \%$, higher than that of copolymer 1a (Table II). Yields were $4.5-25.9 \%$. The relationship of yield and [BdTMS]/[CAn] with molar ratio of BdTMS in the feed as well as that in the case of MAn seems to be the same as for usual charge transfer copolymerization, ${ }^{3-7}$ in which a maximum rate of polymerization was observed at 50/50 monomer feed ratio and [BdTMS]/[CAn] in the copolymer was almost 50/50 in the whole range of molar ratios of BdTMS in the feed (Figure 2). Molecular weights obtained from SEC measurement were $2.31 \times 10^{4}-13.40 \times 10^{4}$, which showed maximum values at the feed molar ratio ([BdTMS $]_{0} /$ $[\mathrm{CAn}]_{0}$ ) of $50 / 50 . M_{\mathrm{w}} / M_{\mathrm{n}}$ s were $2.0-2.8$ irrespective of the feed monomer ratio. These results strongly show that the participation of the CTC must be assumed in the polymerization.

\section{Copolymerization of BdTMS with IAn}

Copolymerization of BdTMS and IAn was carried out under the same condition as that for the copolymerization of BdTMS with MAn or CAn (Table IV). The composition of copolymer 3 was 50/50 irrespective of the feed molar ratio. Copolymer composition was estimated by the ${ }^{1} \mathrm{H}$ NMR peak ratio of peaks at $0.18 \mathrm{ppm}\left[\mathrm{CH}_{2} \mathrm{CHCH}\right.$

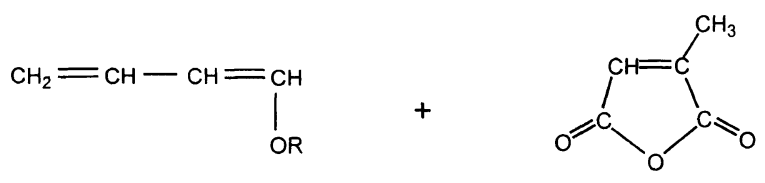

BdTMS, $\mathrm{R}=\mathrm{Si}\left(\mathrm{CH}_{3}\right)_{3}$

Citraconic Anhydride (CAn)

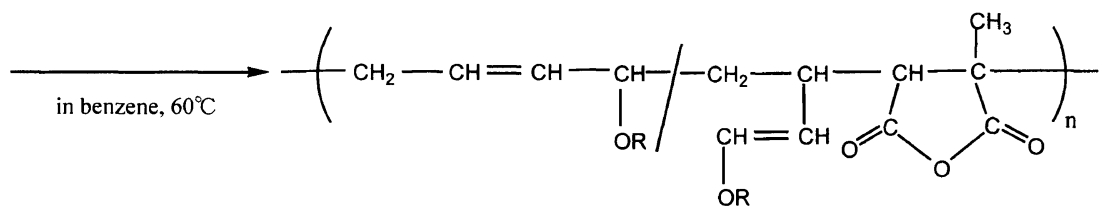

Poly(BdTMS-alt-CAn) (2), $\mathrm{R}=\mathrm{Si}\left(\mathrm{CH}_{3}\right)_{3}$

Scheme 2. Spontaneous copolymerization of BdTMS with CAn.

Table III. Copolymerization of 1-butadienyloxytrimethylsilane (BdTMS) with citraconic anhydride (CAn) ${ }^{\mathrm{a}}$

\begin{tabular}{|c|c|c|c|c|c|c|}
\hline \multirow{2}{*}{ Run } & \multirow{2}{*}[\mathrm{BdTMS}]{$_{0} /[\mathrm{CAn}]_{0}^{\mathrm{b}}$} & Yield & \multirow{2}{*}{$M_{\mathrm{n}}^{\mathrm{c}} \times 10^{-4}$} & \multirow{2}{*}{$M_{\mathrm{w}} / M_{\mathrm{n}}^{\mathrm{c}}$} & \multirow{2}{*}{$\frac{{\text { [BdTMS }] /[\mathrm{CAn}]^{\mathrm{d}}}^{\mathrm{mol} \%}}{\mathrm{~m}}$} & \multirow{2}{*}{$\frac{[1,4 \text {-Addition }] /[3,4 \text {-Addition }]^{\mathrm{e}}}{\mathrm{mol} \%}$} \\
\hline & & $\mathrm{mol} \%$ & & & & \\
\hline 1 & $25 / 75$ & 13.0 & 2.31 & 2.0 & $53 / 47$ & $78 / 22$ \\
\hline 3 & $50 / 50$ & 25.9 & 13.4 & 2.8 & $54 / 46$ & $76 / 24$ \\
\hline 4 & $62 / 38$ & 10.6 & 4.35 & 2.1 & $54 / 46$ & $78 / 22$ \\
\hline 5 & $75 / 25$ & 4.5 & 4.26 & 2.3 & $51 / 49$ & $74 / 26$ \\
\hline
\end{tabular}

${ }^{\mathrm{a}}[\mathrm{BdTMS}]_{0}+[\mathrm{CAn}]_{0}=1.2 \mathrm{~mol} \mathrm{~L}^{-1}$; solv., benzene; temp., $60^{\circ} \mathrm{C}$; time, $8 \mathrm{~h} .{ }^{\mathrm{b}}$ Feed molar ratio of BdTMS to CAn. ${ }^{\mathrm{c}}$ Determined by SEC in THF (polystyrene standards). ${ }^{\mathrm{d}}$ Molar ratio of BdTMS and CAn unit in polymer, determined by ${ }^{1} \mathrm{H}$ NMR in CDCl ${ }_{3}$. ${ }^{\mathrm{e}} \mathrm{Molar}$ ratio of $1,4-$ addition unit to 3,4-addition unit in the polymer, determined by ${ }^{1} \mathrm{H} \mathrm{NMR}$ in $\mathrm{CDCl}_{3}$. 
$\left.=\mathrm{CHOSi}\left(\mathrm{CH}_{3}\right)_{3}\right]$ and $0.03 \mathrm{ppm} \quad\left[\mathrm{CH}_{2} \mathrm{CH}=\mathrm{CHCHOSi}-\right.$ $\left.\left(\mathrm{CH}_{3}\right)_{3}\right]$ and peaks at $2.03-1.43 \mathrm{ppm}$ [ $\left[\mathrm{CH}_{2} \mathrm{CHCH}=\right.$ $\left.\mathrm{CHOSi}\left(\mathrm{CH}_{3}\right)_{3}, \mathrm{CH}_{2} \mathrm{C}\right]$.

BdTMS copolymerized with IAn to give the copolymer rich in cis-1,4 structure by IR measurement. In the spectrum, a remarkable peak was observed at 1660 $\left(v_{\mathrm{H}-\mathrm{C}=\mathrm{C}-\mathrm{H}}\right)$, which corresponded to cis carbon-carbon double bonds. These results show that the participation of the CTC must be assumed in the polymerization. Yields and $M_{\mathrm{n}}$ obtained from SEC measurement were $4.5-25.9 \%$ and $1.84 \times 10^{4}-6.94 \times 10^{4}$, respectively. Yield and $M_{\mathrm{n}}$ were maximum at the feed ratio

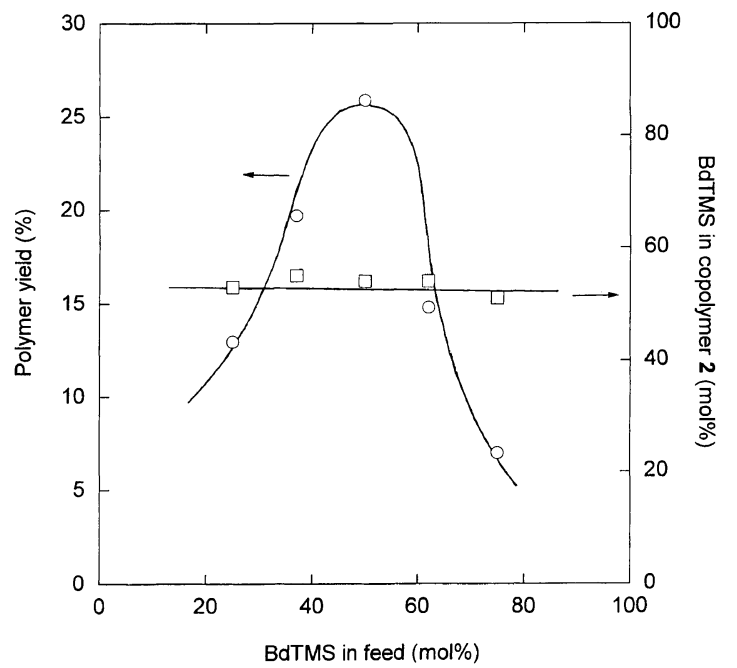

Figure 2. Effects of monomer feed ratio on the polymer yield $(\bigcirc)$ and copolymer composition ( $\square$ ) in the copolymerization of BdTMS and CAn in benzene.
([BdTMS $]_{0} /[\mathrm{IAn}]_{0}$ ) of $50 / 50$, as noted for the copolymerization of BdTMS with MAn or CAn (Tables II or III). However, peaks ascribed to methyl protons (1.34 ppm) and methine protons $(2.62 \mathrm{ppm})$ of CAn unit were observed in the ${ }^{1} \mathrm{H}$ NMR spectra, indicating isomerization from IAn unit into CAn unit. Molar ratios of IAn unit to CAn unit estimated from a peak intensity ratio of peak at $1.34 \mathrm{ppm}\left(\mathrm{CH}_{3}\right.$ of $\mathrm{CAn}$ unit $)$ and peak at $3.23-2.69$ ppm $\left(\mathrm{CCH}_{2}\right.$ of IAn unit) are summarized in Table IV. Unexpectedly, 31-50\% isomerization was induced except for [BdTMS $]_{0} /[\mathrm{IAn}]_{0}$ of $25 / 75$ (Run 1 in Table IV), in which isomerization hardly occurred ([IAn]/[CAn] = 95/5).

The ratios of 1,4- and 3,4-addition structure in the polymers were $66 / 34-74 / 26$. The addition of the copolymer obtained by the spontaneous copolymerization in this experimental condition seemed to be affected by $K$ of CTC, i.e., binding constant of donor monomer (BdTMS) and acceptor monomer. The higher $K$ was, the greater 1,4-addition was. In the copolymerization of BdTMS with CAn $(K=0.96), 1,4$-addition was $74-78 \%$ in copolymer 2, while for copolymer $\mathbf{1 a}$ derived from BdTMS and MAn $(K=0.44), 61-65 \%$ and copolymer 3 consisting BdTMS and IAn $(K=0.59), 66-74 \%$. This was supported by preliminary results of copolymerization of BdTMS with NPMI under similar conditions $\left([\mathrm{BdTMS}]_{0} /[\mathrm{NPMI}]_{0}=50 / 50\right)$, in which these monomers did not form CTC and the poly(BdTMS-co-NPMI) obtained in the presence of radical initiator (yield, 26\%) showed only $38 \%$ 1,4-addition.

Desilylation and Successive Lactonization of Poly(BdTMS-alt-MAn) (1a)

As the desilylation of $\mathbf{1 a}$ proceeded, a white powder

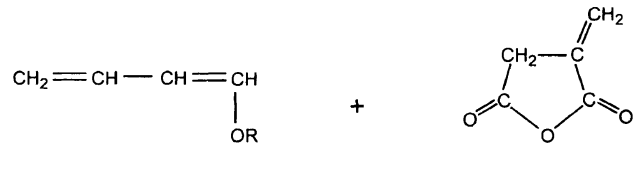

BdTMS, $\mathrm{R}=\mathrm{Si}\left(\mathrm{CH}_{3}\right)_{3} \quad$ Itaconic Anhydride (IAn)

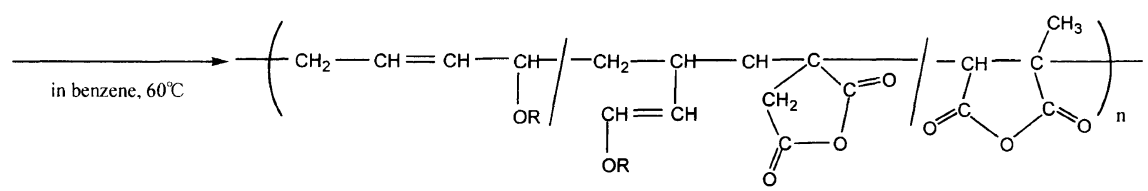

Poly(BdTMS-alt-IAn) $(3), \mathrm{R}=\mathrm{Si}\left(\mathrm{CH}_{3}\right)_{3}$

Scheme 3. Spontaneous copolymerization of BdTMS with IAn.

Table IV. Copolymerization of 1-butadienyloxytrimethylsilane (BdTMS) with itaconic anhydride (IAn) ${ }^{\mathrm{a}}$

\begin{tabular}{|c|c|c|c|c|c|c|c|}
\hline \multirow{2}{*}{ Run } & \multirow{2}{*}[\mathrm{BdTMS}]{$_{0} /[\mathrm{IAn}]_{0}^{\mathrm{b}}$} & Yield & \multirow{2}{*}{$M_{\mathrm{n}}^{\mathrm{c}} \times 10^{-4}$} & \multirow{2}{*}{$M_{\mathrm{w}} / M_{\mathrm{n}}^{\mathrm{c}}$} & \multirow{2}{*}{$\frac{[\mathrm{BdTMS}] /[\mathrm{IAn}]^{\mathrm{d}}}{\mathrm{mol} \%}$} & \multirow{2}{*}{$\begin{array}{c}{[1,4 \text {-Addition }] /[3,4 \text {-Addition }]^{\mathrm{e}}} \\
\operatorname{mol} \%\end{array}$} & \multirow{2}{*}{$\frac{[\mathrm{IAn}] /[\mathrm{CAn}]^{\mathrm{f}}}{\mathrm{mol} \%}$} \\
\hline & & $\mathrm{mol} \%$ & & & & & \\
\hline 1 & $25 / 75$ & 13.6 & 1.87 & 3.0 & $49 / 51$ & $66 / 34$ & $95 / 5$ \\
\hline 2 & $37 / 63$ & 14.8 & 2.68 & 2.7 & $50 / 50$ & $66 / 34$ & $69 / 31$ \\
\hline 3 & $50 / 50$ & 15.4 & 6.94 & 1.9 & $52 / 48$ & $67 / 33$ & $56 / 44$ \\
\hline 4 & $62 / 38$ & 14.8 & 4.58 & 1.7 & $49 / 51$ & $66 / 34$ & $50 / 50$ \\
\hline 5 & $75 / 25$ & 7.0 & 1.84 & 2.9 & $49 / 51$ & $74 / 26$ & $63 / 37$ \\
\hline
\end{tabular}

${ }^{\mathrm{a}}[\mathrm{BdTMS}]_{0}+[\mathrm{IAn}]_{0}=1.2 \mathrm{~mol} \mathrm{~L}^{-1}$; solv., benzene; temp., $60^{\circ} \mathrm{C}$; time, $8 \mathrm{~h} .{ }^{\mathrm{b}}$ Feed molar of BdTMS to IAn. ${ }^{\mathrm{c}}$ Determined by SEC in THF (polystyrene standards). ${ }^{\mathrm{d}}$ Molar ratio of BdTMS to IAn unit in polymer, determined by ${ }^{1} \mathrm{H} \mathrm{NMR} \mathrm{in} \mathrm{CDCl}_{3}$. ${ }^{\mathrm{e}} \mathrm{Molar}^{\mathrm{Natio}}$ of 1,4 -addition unit to 3,4-addition unit in polymer, determined by ${ }^{1} \mathrm{H} \mathrm{NMR}$ in $\mathrm{CDCl}_{3}$. ${ }^{\mathrm{f}}$ Molar ratio of IAn unit to CAn unit in the polymer, determined by ${ }^{1} \mathrm{H} \mathrm{NMR}$ in $\mathrm{CDCl}_{3}$. 


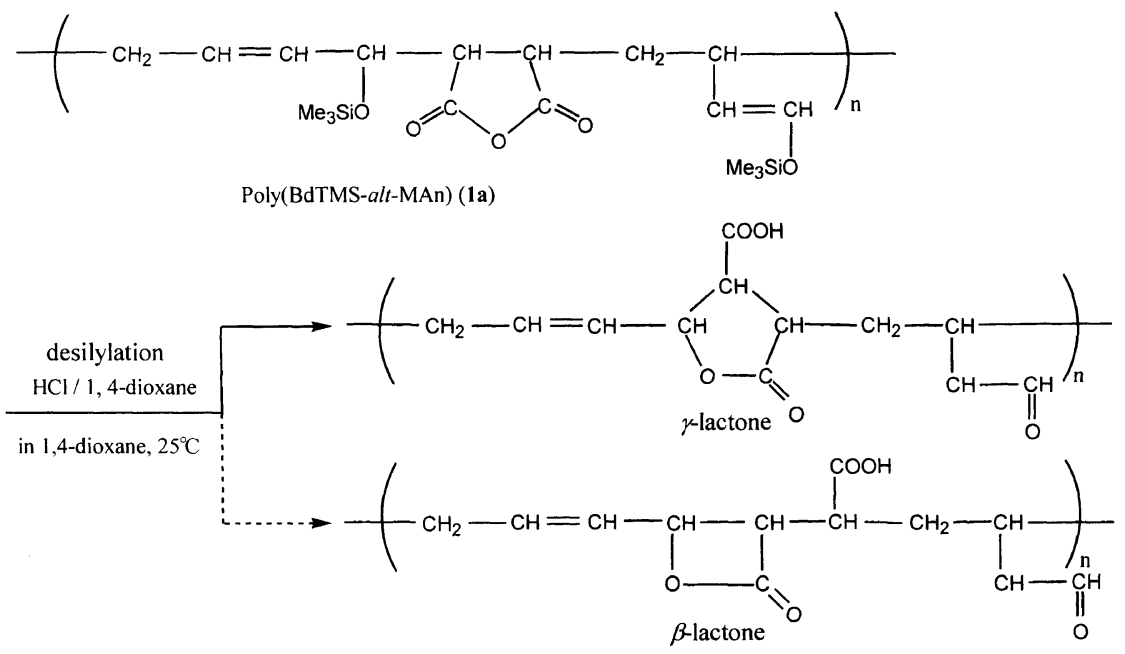

Scheme 4. Desilylation and lactonization of poly(BdTMS-alt-MAn) (1a).

was precipitated. The precipitate was insoluble in water and other common solvents expect for DMSO and hot DMF. Although intermolecular reactions were possible, they may result in extensive gelation and the polymer obtained may not be soluble in solvents. This experimental conditions, it was considered that an itramolecular reaction takes place predominantly. ${ }^{1} \mathrm{H}$ NMR measurements in DMSO- $d_{6}$ revealed the formation of lactone ring in the main chain clearly. The peak due to the silyl group (0.19 and $0.07 \mathrm{ppm}$ ) disappeared completely, and a sharp peak due to oxymethine protons in the fivemembered lactone (Scheme 4) appeared at $5.03 \mathrm{ppm}$. There are two possible lactone structures, $\beta$ - or $\gamma$ lactones by intramolecular reactions (Scheme 4). $\gamma$ Hydroxyl acid cyclizes to stable $\gamma$-lactone by heating, whereas $\beta$-lactone formation is difficult. In the IR spectrum, absorbance ascribed to carbonyl stretching was observed at $1779 \mathrm{~cm}^{-1}$ (Figure 3) which should be assigned not to that of $\beta$-lactone $\left(1825-1820 \mathrm{~cm}^{-1}\right)$ but that of $\gamma$ lactone $\left(1780-1760 \mathrm{~cm}^{-1}\right)$. The hydroxyl group produced by the desilylation thus attacks the neighboring cyclic anhydride group intramolecularly, causing its conversion to a five-membered lactone unit. The conversion of lactonization determined by ${ }^{1} \mathrm{H}$ NMR peak intensity ratio (at $6.00-5.40 \mathrm{ppm}$ and at $5.26,5.03 \mathrm{ppm}$ ) often exceeded $86.5 \%$ (Flory's limit ${ }^{27}$ ) and was nearly $100 \%$. The high reactivity might be due to the alternating copolymer 1a containing always one cyclic anhydride group, i.e., two carbonyl group, and hydroxyl group per the repeating unit after desilylation. The pair groups are separated from the neighboring pair units by a spacer containing rigid double bonds. It is considered that the lactonization may be affected by configuration or conformation of 1a. As shown theoretically in preceding papers, ${ }^{28}$ near $100 \%$ conversion of intramolecular reactions in copolymer consisting of two alternating units, $A-D_{1}, A-D_{2}$, is possible, when $A-D_{2}$ could not bring about any reaction. Thus, the copolymers $\mathbf{1 a}$ in this paper can be regarded as a profitable model for a "specially-designed alternating copolymer". ${ }^{28}$

IR analysis of 1a after desilylation clarified the geometrical structure of the silyloxy diene unit in the copolymer 1a quantitatively according to the same method

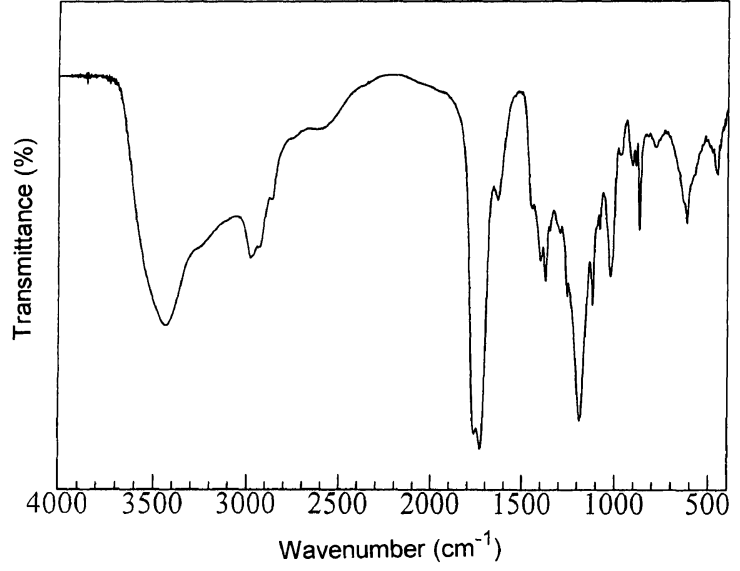

Figure 3. IR spectrum of poly (BdTMS-alt-MAn) (1a) after desilylation (KBr disk).

for the copolymer consisting of butadiene and maleic anhydride ${ }^{33}$ using Morero's extinction coefficient. ${ }^{34}$ From the peak ratio at $978 \mathrm{~cm}^{-1}\left[\delta_{\mathrm{H}-\mathrm{C}=\mathrm{C}-\mathrm{H}}(\right.$ trans $\left.)\right]$ and at 754 $\mathrm{cm}^{-1}\left[\delta_{\mathrm{H}-\mathrm{C}=\mathrm{C}-\mathrm{H}}(\mathrm{cis})\right]$, the 1,4-cis structure was determined to be $91 \%$. Before desilylation, peaks overlapped with those ascribed to silyl groups $\left(v_{\mathrm{Si}-\mathrm{O}}\right)$. The results support the spontaneous copolymerization of BdTMS and MAn.

\section{CONCLUSION}

1-Silyloxy-1,3-dienes, BdTMS and BdTBDMS, were copolymerized with unsaturated cyclic anhydrides (MAn, CAn, and IAn) without any initiator in benzene. The copolymers with almost a 1:1 molar ratio of the cyclic anhydrides and silyloxydiene were obtained in a wide range of feed compositions. Binding constant $K$ of CTC influenced the addition form of the silyloxydiene unit in the alternating copolymer, which may lead to structural regulation of the polymer by intermolecular interactions between monomers. Desilylation and lactonization of poly(BdTMS-alt-MAn) (1a) revealed that alternating copolymer 1a was a model polymer, in which the conversion of lactonization exceeded Flory's limit 
(86.5\%) at nearly $100 \%$.

Acknowledgment. The authors acknowledge the financial contribution from Iwata Chemical Co., Ltd. (Shizuoka, Japan).

\section{REFERENCES}

1. J. M. G. Cowie, Ed., "Alternating Copolymers," Plenum Publishing Corporation, New York, N.Y., 1985, p 19.

2. P. D. Bartlett and K. Nozaki, J. Am. Chem. Soc., 68, 1495 (1946).

3. T. Saegusa, Angew. Chem., Int. Ed. Engl., 16, 826 (1977).

4. H. K. Hall, Jr., Angew. Chem., Int. Ed. Engl., 22, 440 (1983).

5. T. Sato, M. Abe, and T. Otsu, Makromol. Chem., 178, 1061 (1977).

6. T. Kokubo, S. Iwatsuki, and Y. Yamashita, Macromolecules, 1, 482 (1968).

7. G. Goksel, B. Hacioglu, and U. Akbulut, J. Polym. Sci., Part A: Polym. Chem., 24, 1487 (1997).

8. S. Danishefsky and T. Kitahara, J. Am. Chem. Soc., 96, 7807 (1974).

9. S. Danishefsky and T. Kitahara, J. Org. Chem., 40, 539 (1975).

10. W. R. Rousch and D. S. Coffey, J. Org. Chem., 60, 539 (1995).

11. R. G. F. Giles, I. R. Green, M. L. Given, and S. C. Yorke, J. Chem. Soc. Perkin Trans. 1, 2459 (1988).

12. M. A. Brimble and R. J. R. Elliott, Tetrahedron, 53, 7715 (1997).

13. M. E. Jung and N. Nishimura, J. Am. Chem. Soc., 121, 3529 (1999).

14. E. M. Smith, Tetrahedron Lett., 40, 3285 (1999).

15. T. Hirabayashi, T. Ito, and K. Yokota, Polym. J., 20, 1041 (1988).

16. T. Hirabayashi, T. Kawasaki, and K. Yokota, Polym. J., 22,
287 (1990).

17. H. Sumi, T. Hirabayashi, Y. Inai, and K. Yokota, Polym. J., 24, 1041 (1992).

18. H. Sumi, A. Suzuki, T. Hirabayashi, Y. Inai, and K. Yokota, Polym. J., 26, 705 (1994).

19. Y. Mori, H. Sumi, T. Hirabayashi, Y. Inai, and K. Yokota, Macromolecules, 27, 1051 (1994).

20. H. Sumi, T. Noto, Y. Inai, T. Hirabayashi, and K. Yokota, Polym. J., 26, 1080 (1994)

21. T. Kobayashi, Process Biochem., 2, 61 (1967).

22. R. Narayan, 'Emerging Technologies for Materials and Chemicals from Biomass,' in "ACS Symposium Series 476", R. W. Rowell, T. P. Schultz, and R. Narayan, Ed., American Chemical Society, Washington, D.C., 1992, p 1.

23. A. Takasu, M. Ito, Y. Inai, T. Hirabayashi, and Y. Nishimura, Polym. J., 31, 961 (1999).

24. S. Takenouchi, A. Takasu, Y. Inai, T. Hirabayashi, Polym. Prepr., Jpn., 49, E 956 (2000).

25. T. Shimizu, M. Yoshikawa, M. Hasegawa, and H. Chiba, Kobunshi Ronbunshu, 34, 753 (1977).

26. M. Hirooka, K. Takeya, Y. Uno, A. Yamane, and K. Maruyama, Ger. Patent 2065345 (May 3, 1973).

27. P. Flory, J. Am. Chem. Soc., 61, 1518 (1939).

28. T. Hirabayashi and K. Yokota, Polym. J., 13, 51 (1981).

29. H. A. Benesi and J. H. Hildebrand, J. Am. Chem. Soc., 71, 2703 (1949).

30. P. Peyser, in "Polymer Handbook", 3rd ed, J. Brandrup, E. H. Immergut, Ed., John Wiley \& Sons, Inc., New York, N. Y., 1989.

31. T. Kokubo, S. Iwatsuki, and Y. Yamashita, Macromolecules, 1, 482 (1968).

32. R. B. Woodward and J. J. Katz, Tetrahedron, 5, 70 (1959).

33. Y. Yamashita, S. Iwatsuki, and T. Kokubo, J. Polym. Sci., C, 23, 753 (1968).

34. D. Morero, A. Santambrogio, L. Porri, and F. Cliampelli, Chim. Ind. (Milan), 41, 758 (1959). 